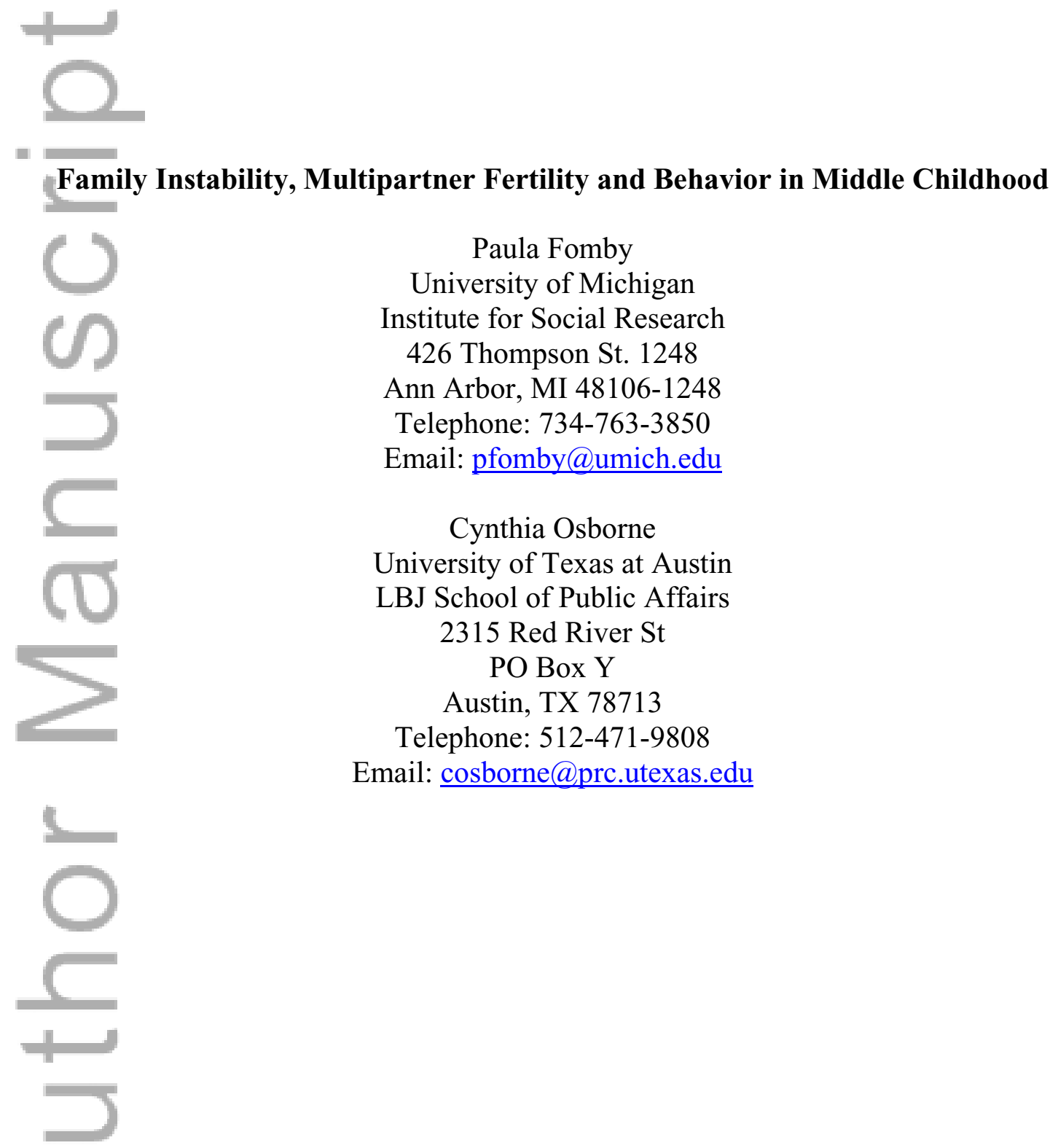

Acknowledgements: An earlier version of this manuscript was presented at the 2013 annual meeting of the Population Association of America. We are grateful to Megan Sweeney, the

This is the author manuscript accepted for publication and has undergone full peer review but has not been through the copyediting, typesetting, pagination and proofreading process, which may lead to differences between this version and the Version of Record. Please cite this article as doi: $10.1111 /$ jomf.12349

This article is protected by copyright. All rights reserved. 
editor, and four anonymous reviewers for their constructive comments and suggestions. All errors and omissions are the responsibility of the authors.

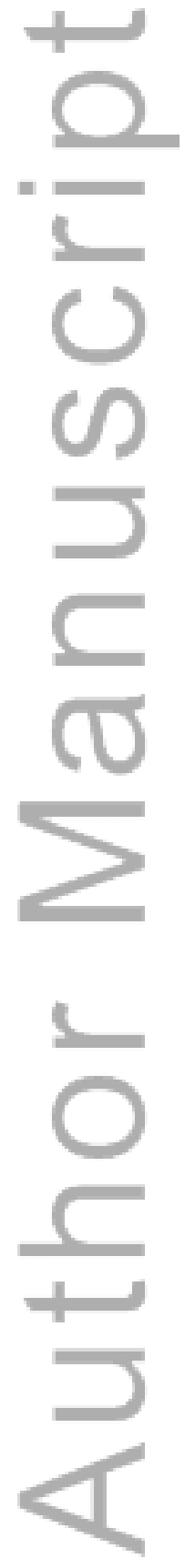

This article is protected by copyright. All rights reserved. 


\begin{abstract}
$\underline{\text { Abstract }}$
Two concepts capture the dynamic and complex nature of contemporary family structure: family instability and multipartner fertility. Although these circumstances are likely to co-occur, their respective literatures have proceeded largely independently. We used data from the Fragile Families and Child Wellbeing Study $(\mathrm{N}=3,062)$ to consider these dimensions of dynamic family structure together, asking whether they independently predict children's behavior problems at age 9. Frequent family instability was consistently predictive of higher predicted levels of behavior problems for children born to unmarried mothers, an association largely attenuated by factors related to family stress. Multipartner fertility was robustly related to self-reported delinquency and teacher-reported behavior problems among children born to married mothers. Keywords: behavior; family dynamics; family structure; fertility
\end{abstract}




\section{Family Instability, Multipartner Fertility and Behavior in Middle Childhood}

Two concepts capture the increasingly dynamic and complex nature of contemporary family structure: family instability and multipartner fertility. Family instability is defined as repeated changes in a child's family structure, and is often measured as a count of the entrances and exits by a biological parent's romantic partners or spouses into or out of a child's household (Fomby and Cherlin 2007, Osborne and McLanahan 2007, Wu and Martinson 1993). Multipartner fertility is defined as a parent's experience of having biological children with more than one partner during his or her lifetime (Carlson and Furstenberg 2006, Guzzo 2014).

Children's experience of both family instability and multipartner fertility has become more frequent in the last half century in response to rising and then plateauing rates of divorce and remarriage and a steady increase in the prevalence of nonmarital childbearing among unpartnered or cohabiting parents (Cancian, Meyer and Cook 2011, Cavanagh 2008, Osborne and McLanahan 2007, Ryan and Claessens 2012). These aspects of family structure change have largely been considered separately, but it is likely that family instability and multipartner fertility co-occur. For example, when a child's parent dissolves one union and begins another, the parent may have an additional child with his or her new partner. Under those circumstances, a child experiences both family instability (the dissolution of one union and the formation of another) and multipartner fertility (the addition of a half-sibling to his or her family tree). Each type of family change is associated with children's compromised well-being, and particularly with higher rates of externalizing behavior problems, delinquency, and risky behavior across the early life course (Bronte-Tinkew, Horowitz and Scott 2009, Carlson and Furstenberg 2006, Cavanagh 
and Huston 2008, Fomby and Cherlin 2007, Gennetian 2005, Halpern-Meekin and Tach 2008, Lee and McLanahan 2015, Osborne and McLanahan 2007).

Despite the potential co-occurrence of these phenomena and their shared association with compromised behavior outcomes, little scholarship has considered their independent or common association with child well-being. Rather, these two literatures have developed in parallel, considering separate but related reasons that family instability or multipartner fertility would be associated with children's behavior. We propose that a comprehensive view of dynamic family structure accounting for parents' union status change and multipartner fertility will better characterize children's family systems and potentially expose circumstances in complex families where children may experience diminished access to family-based resources or lower relationship quality with parents and siblings.

We assess the independent association of family instability and multipartner fertility with children's externalizing and delinquent behavior in middle childhood, at age 9. We draw on two theoretical perspectives to consider why family instability and multipartner fertility may each relate to children's behavior: family stress and family boundary ambiguity. Children's externalizing behavior and delinquency are outcomes of particular interest because of their robust association with both family instability and multipartner fertility across a range of age groups and social contexts (Bronte-Tinkew, Horowitz and Scott 2009, Cavanagh and Huston 2006, Fomby and Cherlin 2007, Fomby 2011, Ryan and Claessens 2012).

\section{Background}

Family instability and multipartner fertility occur among a significant share of U.S. children. 
Approximately 18 percent of adolescents interviewed in the mid-1990s had experienced two or more changes in family structure (Cavanagh 2008), and estimates from a nationallyrepresentative sample of children born in 2001 indicate that the prevalence of family instability has held steady or increased since then: about 10 percent of children had experienced two or more changes in family structure by school entry (author). Family instability is more common among children born to unmarried parents. Using data from the Fragile Families and Child Wellbeing Study, Osborne and McLanahan (2007) found that over one-third of children born to unmarried mothers had experienced two or more changes in union status by age 3 , including the mother's dating relationships.

Drawing on a variety of data sources and methodologies, scholars have established a robust association between the experience of family instability and externalizing behavior, aggressive behavior, and delinquency across childhood and adolescence (Cavanagh and Huston 2008, Cavanagh and Huston 2006, Cavanagh 2008, Cooper et al. 2011, Fomby and Cherlin 2007, Fomby 2011, Lee and McLanahan 2015, Magnuson and Berger 2009, Osborne and McLanahan 2007, Ryan and Claessens 2012). Hypotheses concerning income volatility (Wu 1996), relationship quality between parents and children (Cavanagh and Huston 2006), parental selection into unstable unions (Fomby and Cherlin 2007), and maternal stress (Osborne and McLanahan 2007) have partially explained this association.

Another literature has documented the increase in multipartner fertility in the United States and its association with children's behavior. Using data from the Fragile Families Study to describe children born in large U.S. cities, Carlson and Furstenberg (2006) reported that more 
than one-third of births occurred to parents in which the mother or father had at least one child with a previous partner. Administrative data from Wisconsin show that 60 percent of firstborn children with unmarried parents in 1997 had at least one half-sibling through their mother or father by age 10 (Cancian, Meyer and Cook 2011). Nationally, at least one in eight children resides in a complex household with half- or step-siblings (Manning, Brown and Stykes 2014), and one in six children in a recent birth cohort was is in a complex household at age 4 (author).

As with family instability, multipartner fertility is associated with children's aggressive behavior across the early life course. Using data from the Fragile Families Study, BronteTinkew, Horowitz, and Scott (2009) found that father's multipartner fertility was associated with children's aggressive behavior at age 3, both directly and indirectly through paternal depression. In research on nationally-representative samples, co-residence with half-siblings has also been positively associated with children's aggressive behavior at school entry and with poorer academic performance and higher levels of delinquency, school detachment, and depression in adolescence (author, Halpern-Meekin and Tach 2008).

\section{Theoretical Perspectives}

Research in the areas of family instability and multipartner fertility are largely informed by theoretical perspectives on family stress and family boundary ambiguity. These perspectives predict that both types of family change will precipitate the retreat of some primary relationships in children's lives and the formation of others, while at the same time influencing the nature of ongoing relationships.

Family stress theory 
Family stress theory asserts that stressful events, such as a union transition or the addition of a new sibling in a household, may destabilize the family system and lead to negative child outcomes because of the associated changes in household resources and routines (George 1989, George 1993, Hill 1949, McCubbin and Patterson 1982). Over time, in the absence of additional stressful events, families may adapt to these changes (Acock and Demo, 1994; Williams and Umberson, 2004). Yet, families who experience repeated changes in partnerships or who have children with multiple partners may be at the greatest risk of negative outcomes because the stress associated with each event is cumulative and families may have relatively little time to adapt before a new change occurs (Rutter, 1983). Family stress theory predicts that a parent's changing union status or the presence of a new sibling through multipartner fertility will disproportionately challenge children to adapt to family disequilibrium if unstable or complex families have fewer resources or a narrower set of coping strategies compared to children in stable families or children whose siblings share a biological father.

One line of family stress theory has considered how parenting and parent-child relationship quality co-occur with or condition the experience of family change. Using data from the Fragile Families Study, Osborne and McLanahan (2007) found that maternal stress and parenting behavior almost entirely attenuated the association between family instability and aggressive behavior when children were 3 years old. In the same sample, Beck and colleagues (2010) documented that more frequent and more recent union status transitions were associated with higher levels of harsh maternal parenting, and among highly-educated mothers, with reduced literacy activities when children were 5 years old. Using data from a sample that included more 
suburban households, Cavanagh and Huston (2006) found that mother's supportiveness and encouragement during mother-child interactions moderated the association of family instability with disruptive behavior in school at 6 years old.

Family stress theory has also provided a framework for documenting that maternal wellbeing is associated with both family instability and multipartner fertility and with children's $=$ early behavior problems. In the family instability literature, research drawing on the Fragile Families Study has shown that co-residential and dating transitions are associated with material hardship, frequent residential mobility, maternal parenting stress, and poorer maternal physical and mental health (Beck et al. 2010, Cooper et al. 2009, Fomby and Sennott 2013, Meadows, McLanahan and Brooks-Gunn 2008, Osborne, Berger and Magnuson 2012). In the literature on multipartner fertility drawn from the same data, [author] found that women who engaged in multipartner fertility were more likely to experience increased parenting stress and depression compared to mothers whose children shared the same biological father. Turney and Carlson (2011) found that both mothers and fathers who experienced multipartner fertility had a higher likelihood of depression.

\section{Family boundary ambiguity}

Family boundary ambiguity is defined by a lack of clarity about who is in and who is outside of a family system and about the roles and responsibilities of individuals within a family system (Stewart 2005). This perspective highlights that for mothers, biological fathers, and social fathers, complex family organization introduces uncertainty about roles, relationships, and responsibilities to each other and to children (Berger and Bzostek 2014, Cherlin 1978, 
McLanahan 2010). When a parent (most often the mother in extant research) has a child with a new partner, she negotiates changing dynamics within the reconstituted family, particularly where the new partner becomes a social father to older children. For example, the biological father may become less certain of his role and identity when a new father figure assumes his former responsibilities (Berger and Bzostek 2014, Guzzo 2009). Second, the social parent may introduce competing ideas about childrearing or provide different levels of care for his biological children compared to nonbiological children in the household (Hofferth and Anderson 2003), a circumstance that may influence relationship quality between siblings, as well as between parents and children (Hetherington et al. 1999, Sweeney 2010). Third, a mother's relationship with her older children may change in response to new caregiving responsibilities, as well as the management of her relationship with their biological father and the father of her youngest child.

These expectations have been supported by research highlighting involvement with children by nonresident fathers and extended kin. Father involvement, represented by time investments and instrumental support provided to children and child support payments to mothers, is more likely to decline when either parent re-partners compared to when both parents remain single, and is more influenced by mothers' than fathers' new relationship formation (Berger, Cancian and Meyer 2012, Tach, Mincy and Edin 2010). More broadly, Harknett and Knab (2007) found that mothers' perceived kin support decreased after having a child with a new partner, an indication that available extended kinship contracts in response to multipartner fertility. The authors concluded that although multipartner fertility connected mothers to multiple kin networks through the fathers of their children, those networks were more diffuse or were 
characterized by boundary ambiguity in which patterns of responsibility and reciprocity were less clearly articulated compared to other systems of family organization.

A distinction between the family stress and family boundary ambiguity perspectives pertains to when family change events occur relative to a child's birth. The family stress perspective expects that children must be exposed to a stressor in order to be influenced by it. That is, family stress theory would predict that only a parent's union instability or multipartner fertility occurring after a child's birth would be associated with that child's well-being. Further, infrequent stressors or stressors followed by a long period of stability should be less consequential for children in the long-run compared to frequent and co-occurring stressors if time enables families to recover from stressful events. In contrast, the family boundary ambiguity perspective considers how the dynamics of a complex and evolving family system may endure to shape the resources and relationships that are available to children. As such, family complexity that emerges even before a child's birth may be associated with children's well-being. We distinguish between mother's multipartner fertility that occurred before or after a child's birth and control for her number of unions prior to the child's birth and whether any union status change or birth through multipartner fertility occurred in the last two years.

\section{Union status at birth}

The literatures on multipartner fertility and family instability have each documented that union status at birth is associated with the likelihood of experiencing family change and potentially conditions the influence of family change on child well-being. Children born to married parents experience greater stability in parents' union status compared to children born to 
cohabiting or unpartnered parents and are also less likely to be born into or to experience parents' multipartner fertility (Cancian, Meyer and Cook 2011, Carlson and Furstenberg 2006, Osborne and McLanahan 2007). Union status at birth also moderates the association of union instability with some child outcomes, including general health, obesity (Bzostek and Beck 2011, Schmeer 2012) and, in the United Kingdom, verbal ability (Fomby 2011), with children born to married parents more negatively affected by subsequent change compared to children born to cohabiting or single parents. Thus, our analysis considers the association of family instability and multipartner fertility with child behavior separately by parents' marital status at the child's birth. The current study

We consider children's experience of family instability and multipartner fertility simultaneously and ask how these components are associated with children's externalizing behavior and early delinquency at age 9, net of one another. Using data from five waves of the Fragile-Families Study, we put the focal child at the center of his or her mother's union formation and childbearing trajectories. Further, we assess whether household and family characteristics that indicate family stress and family boundary ambiguity attenuate the association of each dimension of family change with three reports of children's behavior problems.

We investigate the association between family instability and multipartner fertility and behavior outcomes for children born to married and unmarried mothers separately. We focus on children who lived most or all of the time with their biological mother at each wave, and we measure the mother's union status changes and fertility history to capture union instability and 
multipartner fertility. We acknowledge that a focus on one parent's relationship and fertility history underestimates the total family complexity that children may experience if the other parent also experiences union status changes and new childbearing or if the addition of a stepparent to a child's household brings stepsiblings as well. Data limitations, including a poor response rate from nonresident fathers, preclude an analysis that accounts comprehensively for fathers' subsequent fertility and/or the nature of his involvement with nonresident children. Data and Methods

The Fragile Families and Child Wellbeing Study is a longitudinal birth cohort study including nearly 5,000 children born between 1998 and 2000 in hospitals in 20 U.S. cities with populations of 200,000 or more. The study includes an oversample of children born to unmarried mothers, which enables an assessment of variation within a heterogeneous population. The population represented by the Fragile Families Study is relatively more disadvantaged than the U.S. population as a whole in terms of educational attainment and socioeconomic status (Reichman et al. 2001), and is of interest to family policy advocates, policy makers, and scholars studying social inequality.

Data from the Fragile Families Study have been used frequently to consider family instability and multipartner fertility separately (Beck et al. 2010, Bzostek and Beck 2011, Carlson and Berger 2013, Carlson and Furstenberg 2006, Cooper et al. 2011, Lee and McLanahan 2015, Magnuson and Berger 2009, Osborne and McLanahan 2007, Osborne, Berger and Magnuson 2012, Turney and Carlson 2011). Much of that work has drawn on the family stress perspective to understand the implications of family structure dynamics for child well-being. Thus, we 
bridge two areas of research that have been evaluated separately on a common data source. Moreover, children in the Fragile Families sample have experienced relatively frequent family instability and multipartner fertility compared to the general population. This permits sufficient sample size to make stable estimates of the association between family structure characteristics and children's behavior problems. Further, the sample design permits generalizations to an atrisk population. The tradeoff is that the findings are not necessarily generalizable to families outside of large U.S. cities, particularly for children born to married mothers. However, research with other data sources has documented that family instability and complexity, while less frequent, are similarly consequential for child well-being in the general population (Cavanagh and Huston 2008, Dorius and Guzzo 2013).

Mothers of the children in the Fragile Families sample were interviewed in person within 48 hours of the child's birth and by telephone when the children were 1, 3 and 5 years old. (A subset of households also participated in home visits at the 3-and 5-year follow-ups.) The 9-year follow-up included a telephone interview with the primary caregiver $(\mathrm{N}=3,515)$ and an in-home interview with and observations of the focal child $(\mathrm{N}=3,392$ for observations and 3,377 for the interview). In addition, teachers of focal children were recruited to participate in a mail survey $(\mathrm{N}=2,254)$. The response rate at baseline was 82 percent for unmarried mothers and 87 percent for married mothers. Seventy-two percent of families who participated in the first wave completed the in-home observation and interview at the 9-year follow-up (Bendheim-Thoman Center for Research on Child Wellbeing 2011b). We limited the analysis to include children who had always lived full-time or most of the time with their biological mother at age $9(\mathrm{~N}=3,299)$ in 
order to capture children's exposure to their parent's union and fertility histories. We excluded 237 families with incomplete data on mother-reported union and fertility histories. Our final analytical sample included 3,062 children, 2,327 of whom were born to unmarried mothers and 735 of whom were born to married mothers. (In multivariate analyses, sample sizes vary across outcomes because scores are not available on all items for all children.) We tested supplemental models that restricted the analytic sample to households with at least one other minor child present at age 9 in order to distinguish the association of living with any other children from the association of multipartner fertility or the addition of a new partner's own children in our models. Results were substantively similar to those presented here. We used the age 9 city weight in multivariate analyses to adjust for non-response and unequal probability of selection into the sample. Weighted analyses are representative of children born to women residing in the 20 U.S. cities included in the Fragile Families sample in 1998-2000.

Measures. Family instability was measured as the number of changes a child has experienced in co-resident family structure since birth that resulted from a mother's union dissolution or new union formation. These unions include marriage and cohabitation, but exclude non-coresidential romantic relationships. We did not count a transition from cohabitation to marriage as a union status change from the child's perspective (Manning, Smock and Majumdar 2004). Where families participated in two consecutive waves, the count of family structure changes incorporated information on union status at the prior and current waves and the respondent's report of unions that began and ended between waves. Where a family missed at least one wave but was observed at the age 9 interview, we used the union history collected at 
that wave to complete the count of family structure changes. (Fourteen percent of families missed at least one intervening wave between birth and age 9.) The variable ranges from 0 to 12 (mean=1.84), with family instability more frequent among children born to unmarried mothers $($ mean $=2.16)$ than married mothers $($ mean= $=84)$. In our multivariate models, we constructed dummy variables from the continuous measure and compared children who experienced one transition, two transitions, or three or more transitions to children who experienced no transitions. We used this coding scheme to manage the skewed distribution of the variable and to distinguish more frequent union status changes that might be more characteristic of highly unstable family contexts from less frequent change. A measure treating union status changes as continuous produced similar results to those presented here.

Multipartner fertility was based on the mother's reported fertility history at the age 9 interview. The mother was asked to identify all of her biological children living in or out of the household and to indicate the biological father of each child. We focused on children who lived in the mother's household at the time of the report, but recognize that the experience of having half-siblings elsewhere may also influence children's behavior and development. Where all children shared the same biological father, the measure took a value of 0 to indicate that the mother did not experience multipartner fertility. The variable ranged from 0 to $6($ mean=.69), with multipartner fertility more frequent among children born to unmarried mothers (mean=.84) than to married mothers (mean=.22). For our multivariate analyses, we constructed two dichotomous indicators of mother's multipartner fertility, one indicating whether the mother had children with at least one other partner prior to the focal child's birth and the other indicating 
whether she had children with another partner after the focal child's birth.

Dependent variables. We considered three measures of children's externalizing behavior and delinquency, each from a different source. Using data from a variety of sources overcomes potential respondent bias and provides insight into how children behave in different contexts. First, children self-reported their early delinquent behavior during the child interview at age 9 $(\mathrm{N}=2,288)$. The scale included 17 items, and children were asked whether they had ever engaged in each behavior listed. These range from sneaking a sip of wine or beer, to trespassing, stealing, vandalizing property, or setting fires. The items were recoded and summed to create a scale ranging from 0 to 17 with high positive skew (alpha $=.70$ ). We used factor analysis to determine whether distinct subtypes of delinquent behavior emerged from the original scale. We found that a single factor solution was most appropriate.

Mothers responded to 111 items from the Child Behavior Checklist, indicating whether each behavior described was never, sometimes, or always true of the focal child $(\mathrm{N}=2,178)$. Twentyseven items measured the underlying construct of externalizing behavior. Externalizing behavior is described as aggressive or rule-breaking behavior that is typically directed outward and in opposition to other individuals or material goods (e.g., vandalism, breaking things), and is distinct from internalizing behavior, which is characterized by symptomatology that reflects depression and anxiety (Achenbach 1992). Examples of externalizing behavior include fighting, arguing, stealing, or breaking items belonging to others. Items in the externalizing behavior scale were recoded to range from 0 (never) to 2 (always) and summed. Values ranged from 0 to 54 with high positive skew (alpha=.89). 
Finally, teachers reported on children's classroom behavior in the mail-back survey $(\mathrm{N}=1,494)$. The teacher indicated whether a child engaged in each of 12 behaviors never, sometimes, often, or very often in the last month. We selected six behaviors from the scale that are characteristic of externalizing behavior - fighting, arguing, threatening/bullying, talking back to adults, getting angry easily, and having temper tantrums (alpha $=.92$ ). The variables were recoded to range from 0 to 3 and summed into a measure ranging from 0 to 18 . Teacher-reported measures of behavior problems are more often missing compared to measures reported by children or mothers. Children raised in stable two-parent families with single partner fertility were more likely than their peers to have teacher-reported behavior problem scores, as were children who are non-Hispanic white and who are more socioeconomically advantaged. The Pearson correlation coefficient for child-reported delinquency and parent-reported externalizing behavior problems was .32; the respective pairwise correlations between these outcomes and teacher-reported problem behavior were .34 and .41 .

Family context. We used indicators of family context that have previously been associated with both family instability and multipartner fertility on the one hand, and children's outcomes on the other, All were measured at age 9 except where noted. We included a five-category measure of the child's household-to-needs ratio with cutpoints at 49, 99, 199, and 299 percent of the federal poverty level to indicate financial hardship, which prior work has demonstrated is a correlate of multipartner fertility and a by-product of family instability (Osborne, Berger and Magnuson 2012, Wu 1996). We treated the variable as ordinal. Results were similar treating it as a categorical measure. We also included an ordinal measure of self-reported maternal general 
health measured by a five-category variable ranging from poor to excellent. Because maternal depression is associated both with family instability (Meadows, McLanahan and Brooks-Gunn 2008, Osborne, Berger and Magnuson 2012) and multipartner fertility (author; Turney and Carlson 2011), we tested whether this mechanism was associated with each type of family change. We used the conservative measure of self-reported maternal depression based on the $=$ Composite International Diagnostic Interview-Short Form, Section A that is provided on the public release of the age 9 data file (Bendheim-Thoman Center for Research on Child Wellbeing 2011a). The measure is dichotomous. Given that prior research has posited that family instability matters for children because of its effect on their relationships with parents (Cavanagh and Huston 2006), we included an index of mother-child closeness based on four items from the child interview (how often mother talks with you about important issues; listens to you; spends time with you; and misses important events [reverse-coded]). We used the average score on the four items for all children who responded to at least two items in the scale. An index of harsh parenting practices (Beck et al. 2010) reported by the child's caregiver (the child's mother in our analytic sample) was based on ten items describing the frequency with which a caregiver shouted or cursed at the child, threatened the child, or used physical discipline (hitting, spanking, slapping, or pinching). Four response categories ranged from never to more than 20 times in the past year. We used the average score for caregivers responding to at least six of the 10 items. Because family instability and family size are associated with residential mobility and this in turn is associated with children's delinquent behaviors (Fomby and Sennott 2013, Haynie and South 2005, South and Haynie 2004), we included the number of residential moves reported by the 
child's mother between birth and age 9 .

To capture previously identified indicators of family boundary ambiguity that are associated with child well-being, our models included the following items: whether the focal child had seen his/her father in the last 30 days (with a control for whether the father is deceased) (Guzzo 2009); whether the biological father had children with another partner (Cancian, Meyer and Cook 2011); the mother's perceived support from family or friends for a financial loan, a place to live, or emergency child care (range $=0$ to 3 ) (Harknett and Knab 2007); and the child's reported relationship quality with half-, step-, and full siblings (Hetherington 1999). The last item is a summed score based on two indicators: whether the child reported never or only sometimes comforting or helping a distressed sibling (vs. often or always) and whether the child reported starting fights with siblings often or always (vs. never or sometimes).

Our models also controlled for mother's race/ethnicity, child sex (1=male) and age in months at the age 9 interview, mother's completed education at the child's birth, whether the mother was depressed at the year 1 interview, whether she used Medicaid as a form of insurance to pay for the child's birth (an indicator of financial hardship at the child's birth), her number of prior unions before the child's birth, child temperament at age 1 , whether any family structure transitions or multipartner fertility occurred in the last two years, and the number of full siblings present in the child's household at age 9 .

We used the mi impute suite of commands in Stata/SE version 14 to impute missing values on covariates to maintain the sample's generalizability and increase sample size. Between 1 and 5 percent of observations were missing on each covariate. In addition to all variables included in 
the analytic model, the imputation model included information on household composition, poverty status, and maternal depression at each wave, Spanish-language status, probability weights, and wave nonresponse. Dependent variables were included in the imputation models, but cases with imputed values were not included in our analytic models (von Hippel 2007). Analyses were conducted on 10 imputed data sets derived from the imputation model.

$=$

Methods. Our multivariate models used negative binomial regression to account for the skewed hature of the dependent variables and results are presented separately for children born to unmarried and married mothers. Given the highly skewed nature of the dependent variables, we assessed whether zero-inflated negative binomial regressions that would account for clustering at zero were more appropriate. In nearly all model specifications, the Vuong test indicated that coefficients from the two methods were statistically equivalent. Because the zero-inflated model was not compatible with multiply-imputed data, we retained the traditional negative binomial regression method.

$\underline{\text { Results }}$

Table 1 summarizes the dependent variables and covariates separately for children born to unmarried or married mothers. Children born to unmarried mothers had significantly higher behavior problem scores reported from all sources $(\mathrm{p}<.05)$. More than half of children born to unmarried mothers experienced two or more changes in residential family structure by age 9 , compared to about one-quarter of children born to married mothers. About 57 percent of children born to unmarried mothers had at least one older or younger sibling with a different father, more than three times the prevalence compared to children born to married parents. (Note that because 
children might have both older and younger siblings through multipartner fertility, these categories are not mutually exclusive.) The co-occurrence of family instability and multipartner fertility was also more frequent among children born to unmarried than to married mothers: nearly half of children born to unmarried mothers had both events in their family histories, compared to about one in eight children born to married mothers. The two subgroups were $=$ similar on child age and gender, maternal Hispanicity, mother-child closeness, and deceased father status, but diverged significantly on all other indicators $(\mathrm{p}<.05)$.

Table 2 describes variation in the outcome measures by family structure history. In the pooled sample, children whose families experienced family instability or multipartner fertility had higher behavior problems scores on adult-reported outcomes compared to children who resided in stable households, but there were no significant differences in self-reported delinquency scores. Group differences in the outcomes by family structure history were less consistent between children born in married and unmarried parent households. Frequent union instability (three changes or more) was associated with higher levels of behavior problems across the three outcomes for children and with the two adult-reported outcomes for children born to unmarried mothers. These patterns generally held for children born to married mothers but were less often statistically significant.

Table 3 to 5 presents results from negative binomial regression models estimating children's predicted behavior scores at age 9 separately for children born to unmarried or married mothers. In each panel, Model 1 describes the association between family instability and self-reported delinquency controlling for background characteristics. Model 2 describes the association 
between mother's multipartner fertility and self-reported delinquency accounting for the same background characteristics. Model 3 includes indicators of family instability and multipartner fertility simultaneously. Model 4 includes covariates representing exposure to family stress and family boundary ambiguity. Coefficients and standard errors associated with control variables were removed from the tables to save space. Results are available from the authors upon request.

Table 3 considers children's self-reported delinquent behavior. The exponentiated value of a given coefficient represents the percentage change in the predicted value of the dependent variable for a one-unit change in the value of the independent variable. Model lin the first panel indicates that experiencing frequent (three or more) residential family transitions was associated with a higher predicted self-reported delinquency score among children born to unmarried mothers $(B=.360, \exp (B)=1.433, p<.05)$. Consistent with the descriptive results summarized in Table 2, a history of multipartner fertility was not associated with more delinquent behavior (Mode12). When history of family instability and multipartner fertility were considered together (Model 3), the coefficient associated with three or more union status changes remained statistically significant. Postestimation tests assessing coefficient equivalence in nested models with multiply imputed data confirmed that accounting for multipartner fertility did not significantly reduce the magnitude of the coefficient associated with three or more transitions compared to the magnitude in Model 2. In Model 4, the association of frequent transitions was reduced in magnitude by about 85 percent and became statistically nonsignificant. Postestimation tests indicated that much of this attenuation was attributable to the inclusion of residential mobility, mother-child closeness, mother's harsh discipline, and sibling relationship quality. 
The second panel documents results from the same sequence of models for children born to married mothers. Model 1 indicates that changes in mothers' union status were not predictive of children's self-reported delinquent behavior. Children who had at least one older sibling through a different father (Model 2) had predicted delinquency scores 1.82 times higher than children who experienced their mother's single-partner fertility $(B=.597, \exp (B)=1.816, p<.10)$. When family instability and multipartner fertility were considered simultaneously (Model 3), older sibling multipartner fertility was predictive of a higher self-reported delinquency score $(\mathrm{p}<.05)$. This association was essentially unchanged when covariates associated with family instability and multipartner fertility were included in Model 4.

Table 4 summarizes results from models estimating a child's predicted mother-reported externalizing behavior score. Focusing first on children born to unmarried mothers, Model 1 shows that experiencing one transition or three or more transitions in family structure was associated with a significantly higher predicted externalizing behavior score compared to children who experience no union transitions. A mother's multipartner fertility after the focal child's birth was also predictive of higher externalizing behavior scores for children born to unmarried mothers $(\mathrm{p}<.05)$. Accounting for both sources of family change simultaneously (Model 3) only minimally reduced the magnitude of the coefficient associated with family structure transitions and subsequent multipartner fertility among children born to unmarried mothers. Accounting for potential confounders (Model 4) reduced the association of frequent family structure transitions and multipartner fertility with externalizing behavior below statistical significance and reduced the magnitude of the association of a single family structure transition with the outcome by about one- 
third $(\mathrm{p}<.05)$. Poverty status and harsh maternal discipline were the strongest attenuators.

The association of each type of family change with externalizing behavior among children born to married mothers was less clear-cut. The magnitude of some associations was similar to that for children born to unmarried mothers, but coefficients did not achieve statistical significance. Children who experienced two transitions had higher predicted externalizing $=$ behavior scores compared to those who experienced no transitions (Model 2, $\mathrm{p}<.10$ ), a relationship that held when multipartner fertility was taken into account and increased in magnitude and significance when other covariates were included (Model 4, $<<.05$ ).

Table 5 summarizes results from models estimating teacher-reported problem behavior. Regardless of parents' marital status at birth, high levels of family instability (three or more changes) were predictive of higher levels of reported problem behavior (Model 1). In baseline models, mother's multipartner fertility was not associated with problem behavior for children in either group (Model 2). When family instability and multipartner fertility were considered together (Model 3), frequent union instability remained statistically significant $(\mathrm{p}<.05)$ for both groups, and the association of having an older sibling through a different father with the outcome became statistically significant for children born to married mothers. These associations were mostly robust to the inclusion of covariates associated with family change (Model 4).

\section{Interaction models}

The preceding models considered family instability and multipartner fertility as independently related to children's behavior in middle childhood. Under this approach, the associations of each type of family change were expected to be additive. That is, where a child 
has experienced a mother's change in union status and her multipartner fertility, their collective predicted impact on that child's behavior score net of other covariates is equal to the transformed sum of the unstandardized coefficients associated with the two types of family change.

Alternatively, family instability and multipartner fertility may interact so that when a child experiences both, the impact on his or her predicted behavior score is greater than (or less than) $=$ the sum of the two events considered independently.

To evaluate this approach, we tested models that interacted the categorical measures of family instability used here with a dichotomous measure of exposure to any maternal multipartner fertility to predict each outcome for children born to married and unmarried mothers separately. (Models not shown; available upon request.) Only the interaction between exposure to one family structure change and any multipartner fertility was statistically significant in the model predicting teacher-reported behavior problems for children born to married mothers. Given the general consistency of the nonsignificant interaction terms, we conclude that the cooccurrence of family instability and multipartner fertility do not compound to have a stronger association with the outcomes considered than what we observed in an additive model.

\section{$\underline{\text { Discussion }}$}

The dynamic and complex nature of contemporary children's experience of family structure is described by two concepts in family demography: family instability and multipartner fertility. Although recent research has documented the prevalence and consequences of these circumstances in children's families, there has been little work to consider the extent to which they co-occur or whether these related events are empirically distinct in their association with 
children's well-being. These are questions of both theoretical and practical significance. We used longitudinal data from the Fragile Families and Child Wellbeing Study to address this gap in the literature. We assessed variation in three measures of children's behavioral development at age 9 as an outcome of exposure to family instability and multipartner fertility. We conducted our analyses separately for children born to unmarried and married women.

We report four main findings. First, family structure transitions and multipartner fertility often co-occur. One in eight children born to married parents and almost one in two children born to unmarried parents in large U.S. cities experience both types of family change by age 9 . Second, both family instability and multipartner fertility are associated with higher levels of behavioral problems in 9-year-old children, but the relationships vary across parents' union status at birth. High levels of family instability (three or more transitions) were positively associated with each of the three outcome measures for children born to unmarried mothers. Union instability was also associated with adult-reported outcomes for children born to married parents: two changes in union status predicted children's significantly higher externalizing behavior scores and three or more transitions predicted higher teacher-reported problem behavior. Multipartner fertility, as indicated by the presence of an older half-sibling in a child's household, was positively and persistently associated with self-reported delinquency and teacherreported behavior problems among children born to married parents only. The presence of a younger half-sibling in the household of a child born to an unmarried mother was positively associated with parent-reported externalizing behavior scores.

Our third main finding is that indicators of family context reflecting family stress theory 
diminished the observed association between family change and child behavior to a greater extent than did those related to family boundary ambiguity. We posited that theoretical development in the area of family structure change should reflect the multiple relationships in children's lives that are shaped by the dynamic and complex nature of contemporary family formation. Ultimately, our results suggested that much of what attenuates the association of $=$ family instability with children's behavior is observed within children's households. Children with a history of family instability also experience greater financial hardship, harsher discipline, and greater residential mobility at age 9 compared to children who experienced no union status change. The salience of these factors is consistent with family stress theory, which predicts that disruptions to the family system have potentially cascading consequences for household resources and parents' and children's coping mechanisms. The more inconsistent association of multipartner fertility with child outcomes was not well-explained by household or nonresident parent characteristics, particularly among children born to married mothers.

We continue to advocate for theories that take into account a broader ecology of family change, but we also caution that this theory building and hypothesis testing will likely require data observed directly across the multiple households that complex families occupy. Childcentered studies including the Fragile Families Study and the Early Childhood Longitudinal Study-Birth Cohort have pursued nonresident parents for this purpose, but the resulting samples tend to be biased in favor of parents who have more frequent contact and better quality relationships with their former partners. As an alternative, the genealogical design of a project like the U.S. Panel Study of Income Dynamics, which follows individuals descended from 
original sample members when they move into separate households, may provide another means to observe the households of sample children and their nonresident sample parents directly.

Fourth, based on post-hoc tests of coefficient equivalence, the magnitude of the association of family instability and multipartner fertility coefficients are similar for children born to married or unmarried mothers, with the exception of the relationship between multipartner fertility and $=$ child-reported delinquency. Some of the coefficients that were statistically insignificant in the married-parent sample might have been significant with a larger sample. These findings are provocative for suggesting that the process of family change is consequential for all children, regardless of the family structure status in which they begin or end up. However, while the observed similarities between children born to married and unmarried mothers are informative, they are not definitive, and should not be regarded as generalizable to children born outside of large U.S. cities. Married mothers in the Fragile Families Study more often identify as Hispanic or non-Hispanic Black, are more likely to lack a high school diploma, and have lower household income on average compared to married mothers in the United States as a whole (Wagmiller 2010). Children born to married parents elsewhere might be better insulated from socioeconomic shocks that result from family instability or multipartner fertility.

This research contributes to the literature on the increasingly dynamic and complex nature of family structure by considering the co-occurrence of two increasingly frequent sources of family change: family instability and multipartner fertility. It also emphasizes the value of a more holistic approach to identifying the social context in which children experience family change, including relationships with mothers, biological fathers, and siblings. We note that our research 
does include several limitations. First, as mentioned above, the results of our analysis are not generalizable to families with children born outside of the 20 U.S. cities included in the Fragile Families sample. Second, the analytic sample is limited to children who have always resided with their biological mother in order to ensure that the children were exposed to their mother's union and fertility histories. Family structure change may have different associations with behavior for children who move away from their mother in response to her new union formation or childbearing. Moreover, we only included the partnership changes and multiple partners of the child's mother, which also underestimates the amount of instability and complexity children are exposed to from their father's relationships. The relationships that maternal and paternal instability and multipartner fertility each have with children's behavior may differ and deserve further exploration. Additionally, we have not taken the developmental timing of family structure transitions or a mother's subsequent multipartner fertility into account here. Our purpose was to determine whether these phenomena had distinctive consequences for children, and we worked with the most parsimonious specifications available to assess this question using outcome measures from multiple reporters available at the age 9 interview. Finally, we focused on children's behavioral problems because of their robust association with family change. Future work should determine the extent to which a broader consideration of family dynamics and complexity is associated with children's health, cognitive, and social well-being, and whether the associations with children's well-being are similar to those for parents' adjustment. As families continue to become more complex and less stable, a more complete understanding of the level, consequences, and mechanisms related to these changes is needed. 
The findings from this analysis also have important implications for policy that aims to strengthen families. As children's lives become more complex and less stable, they will need additional supports to offset the stressors brought about by family change. Social programs typically do not assess the level of family instability or complexity a mother or child has experienced, and therefore miss an opportunity to target interventions that may ameliorate $=$ changes in resources and emotional support that family change precipitates.

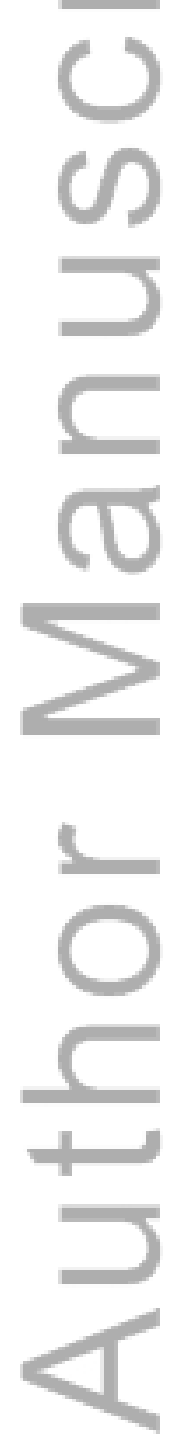




\section{$\underline{\text { References }}$}

Achenbach, Thomas M. 1992. Manual for the Child Behavior Checklist 4/18 and 1991 Profile.

Burlington, VT: Department of Psychiatry, University of Vermont.

Beck, Audrey N., Carey E. Cooper, Sara McLanahan and Jeanne Brooks-Gunn. 2010. "Partnership

Transitions and Maternal Parenting." Journal of Marriage and Family 72(2):219-33.

Bendheim-Thoman Center for Research on Child Wellbeing. 2011a. "Scales Documentation and Question

= Sources for the Nine-Year Wave of the Fragile Families and Child Wellbeing Study." Princeton, NJ: Princeton University.

Bendheim-Thoman Center for Research on Child Wellbeing. 2011b. "Data User's Guide for the NineYear Follow-up Wave of the Fragile Families and Child Wellbeing Study." Vol. Princeton, NJ: Princeton University.

Berger, Lawrence M., Maria Cancian and Daniel L. Meyer. 2012. "Maternal Re-Partnering and NewPartner Fertility: Associations with Nonresident Father Investments in Children." Children and Youth Services Review 34:426-36.

Berger, Lawrence M. and Sharon H. Bzostek. 2014. "Young Adults' Roles as Partners and Parents in the Context of Family Complexity." The ANNALS of the American Academy of Political and Social Science 654(1):87-109.

Bronte-Tinkew, Jacinta, Allison Horowitz and Mindy E. Scott. 2009. "Fathering with Multiple Partners: Links to Children's Well-Being in Early Childhood." Journal of Marriage and Family 71(3 ):60831.

Bzostek, Sharon H. and Audrey N. Beck. 2011. "Family Instability and Young Children's Physical Health ". Social Science and Medicine 73(2):282-92.

Cancian, Maria, Daniel R. Meyer and Steven Cook. 2011. "The Evolution of Family Complexity from the Perspective of Nonmarital Children." Demography 48(3):957-82.

Carlson, M. J. and L. M. Berger. 2013. "What Kids Get from Parents: Packages of Parental Involvement -across Complex Family Forms." Social Service Review 87(2):213-49. doi: 10.1086/671015.

Carlson, Marcia J. and Frank F. Furstenberg. 2006. "The Prevalence and Correlates of Multipartnered Fertility among Urban U.S. Parents." Journal of Marriage and Family 68(August):718-32. 
Cavanagh, S. E. and A. C. Huston. 2008. "The Timing of Family Instability and Children's Social Development." Journal of Marriage and Family 70(5):1258-70. doi: 10.1111/j.17413737.2008.00564.x.

Cavanagh, Shannon E. and Aletha C. Huston. 2006. "Family Instability and Children's Early Problem Behavior." Social Forces 85(1):551-81.

Cavanagh, Shannon E. 2008. "Family Structure History and Adolescent Adjustment." Journal of Family Issues 29(7):944-80. doi: 10.1177/0192513x07311232.

Cherlin, Andrew J. 1978. "Remarriage as an Incomplete Institution." American Journal of Sociology 86:636-50.

Cooper, C. E., C. A. Osborne, A. N. Beck and S. S. McLanahan. 2011. "Partnership Instability, School Readiness, and Gender Disparities." Sociology of Education 84(3):246-59. doi: 10.1177/0038040711402361.

Cooper, Carey E., Sarah O. Meadows, Sara McLanahan and Jeanne Brooks-Gunn. 2009. "Family Structure Transitions and Maternal Parenting Stress." Journal of Marriage and Family 71(3):55874.

Dorius, Cassandra and Karen Benjamin Guzzo. 2013. "Maternal Multipartnered Fertility and Adolescent Well-Being " Paper presented at the Annual Meeting of the American Sociological Association, New York, NY.

Fomby, P. and A. J. Cherlin. 2007. "Family Instability and Child Well-Being." American Sociological Review 72(2):181-204.

Fomby, Paula. 2011. "Family Instability and School Readiness in the United Kingdom." Family Science $2(3): 171-85$.

Fomby, Paula and Christie Sennott. 2013. "Family Structure Instability and Mobility: The Consequences for Adolescents' Problem Behavior." Social Science Research 42(181-206). doi: http://dx.doi.org/10.1016/j.ssresearch.2012.08.016.

Gennetian, L. 2005. "One or Two Parents? Half or Step Siblings? The Effect of Family Structure on Young Children's Achievement." Journal of Population Economics 18(3):415-36. doi: 10.1007/s00148-004-0215-0.

George, Linda. 1989. "Stress, Social Support, and Depression over the Life Course." Pp. 290 in Aging, Stress, and Health, edited by K. S. Markides and C. L. Cooper. Chicester, UK: Wiley. 
George, Linda. 1993. "Sociological Perspectives on Life Transitions." Annual Review of Sociology 19:353-73.

Guzzo, K. B. 2009. "Maternal Relationships and Nonresidential Father Visitation of Children Born Outside of Marriage." Journal of Marriage and Family 71(3):632-49.

Guzzo, Karen Benjamin. 2014. "New Partners, More Kids: Multiple-Partner Fertility in the United States." The ANNALS of the American Academy of Political and Social Science 654(1):66-86. doi: $10.1177 / 0002716214525571$.

Halpern-Meekin, S. and L. Tach. 2008. "Heterogeneity in Two-Parent Families and Adolescent WellBeing." Journal of Marriage and Family 70(2):435-51. doi: 10.1111/j.1741-3737.2008.00492.x.

Harknett, Kristen and Jean Knab. 2007. "More Kin, Less Support: Multipartnered Fertility and Perceived Support among Mothers." Journal of Marriage and Family 69(1):237-53.

Haynie, D. L. and S. J. South. 2005. "Residential Mobility and Adolescent Violence." Social Forces 84(1):361-74.

Hetherington, E. M., S. H. Henderson, T. G. O'Connor, G. M. Insabella, L. C. Taylor, E. R. Anderson, M. J. Skaggs, K. M. Jodl, M. Bridges, J. E. Kim, A. S. Mitchell and R. W. Chan. 1999. "Adolescent Siblings in Stepfamilies: Family Functioning and Adolescent Adjustment." Monographs of the Society for Research in Child Development 64(4):V-209.

Hetherington, E. Mavis. 1999. "Family Functioning and the Adjustment of Adolescent Siblings in Diverse Types of Families." Monographs of the Society for Research in Child Development 64(4):1-25. doi: $10.2307 / 3181537$.

Hill, Reuben. 1949. Families under Stress: Adjustment to the Crisis of War Separation and Reunion. New York: Harper and Brothers.

Hofferth, Sandra L. and Kermyt G. Anderson. 2003. "Are All Dads Equal? Biology Versus Marriage as a Basis for Paternal Investment." Journal of Marriage and Family 65(1):213-32. doi: $10.2307 / 3600061$.

Lee, D. and S. McLanahan. 2015. "Family Structure Transitions and Child Development: Instability, Selection, and Population Heterogeneity." American Sociological Review 80(4):738-63. doi: $10.1177 / 0003122415592129$. 
Magnuson, K. and L. M. Berger. 2009. "Family Structure States and Transitions: Associations with Children's Well-Being During Middle Childhood." Journal of Marriage and Family 71(3):57591.

Manning, W. D., P. J. Smock and D. Majumdar. 2004. "The Relative Stability of Cohabiting and Marital Unions for Children." Population Research and Policy Review 23(2):135-59. doi: 10.1023/B:POPU.0000019916.29156.a7.

Manning, Wendy D., Susan L. Brown and J. Bart Stykes. 2014. "Family Complexity among Children in

" "the United States." The ANNALS of the American Academy of Political and Social Science 654(1):48-65. doi: 10.1177/0002716214524515.

McCubbin, Hamilton I. and Joan M. Patterson. 1982. "Family Adaptation to Crises." in Family Stress, Coping, and Social Support, edited by H. I. McCubbin, A. E. Cauble and J. M. Patterson. Springfield, IL: Charles C. Thomas.

McLanahan, Sara S. 2010. "Family Instability and Complexity after a Nonmarital Birth: Outcomes for "Children in Fragile Families." Vol. Princeton, NJ: Center for Research on Child Wellbeing, Princeton University.

Meadows, Sarah O., Sara McLanahan and Jeanne Brooks-Gunn. 2008. "Stability and Change in Family Structure and Mental Health Trajectories." American Sociological Review 73(2):314-34.

Osborne, Cynthia and Sara McLanahan. 2007. "Partnership Instability and Child Well-Being." Journal of Marriage and Family 69(4):1065-83.

Osborne, Cynthia, Lawrence M. Berger and Katherine Magnuson. 2012. "Family Structure Transitions and Changes in Maternal Resources and Well-Being." Demography 49(1):23-47. doi: -10.1007/s13524-011-0080-x.

Reichman, Nancy, Julien Teitler, Irwin Garfinkel and Sara McLanahan. 2001. "Fragile Families: Sample and Design." Children and Youth Services Review 23(4/5):303-26.

Ryan, Rebecca M. and Amy Claessens. 2012. "Associations between Family Structure Changes and Children's Behavior Problems: The Moderating Effects of Timing and Marital Birth." Developmental Psychology:No Pagination Specified. doi: 10.1037/a0029397.

Schmeer, Kammi K. 2012. "Family Structure and Obesity in Early Childhood." Social Science Research 41(4):820-32. doi: 10.1016/j.ssresearch.2012.01.007. 
South, Scott J. and Dana L. Haynie. 2004. "Friendship Networks of Mobile Adolescents." Social Forces 83(1):315-50.

Stewart, Susan D. 2005. "Boundary Ambiguity in Stepfamilies." Journal of Family Issues 26:1002-29.

Sweeney, M. M. 2010. "Remarriage and Stepfamilies: Strategic Sites for Family Scholarship in the 21st

Centüry." Journal of Marriage and Family 72(3):667-84. doi: 10.1111/j.17413737.2010.00724.x.

Tach, Laura, Ronald Mincy and Kathryn Edin. 2010. "Parenting as A "Package Deal": Relationships,

= "Fertility, and Nonresident Father Involvement among Unmarried Parents." Demography 47(1):181-204.

Turney, Kristin and Marcia J. Carlson. 2011. "Multipartnered Fertility and Depression among Fragile Families." Journal of Marriage and Family 73(3):570-87. doi: 10.1111/j.17413737.2011.00828.x.

von Hippel, Paul T. 2007. "Regression with Missing Ys: An Improved Strategy for Analyzing Multiply "Imputed Data." Sociological Methodology 2007, Vol 37 37:83-117. doi: 10.1111/j.14679531.2007.00180.x.

Wagmiller, Robert L. 2010. "How Representative Are the Fragile Families Study Families?: A Comparison of the Early Childhood Longitudinal Study-Birth Cohort and Fragile Families Samples ". Princeton, NJ: The Bendheim-Thoman Center for Research on Child Wellbeing.

Wu, Lawrence L. and Brian C. Martinson. 1993. "Family Structure and the Risk of a Premarital Birth." American Sociological Review 58(2):210-32.

Wu, Lawrence L. 1996. "Effects of Family Instability, Income, and Income Instability on the Risk of a Premarital Birth." American Sociological Review 61(3):386-406.

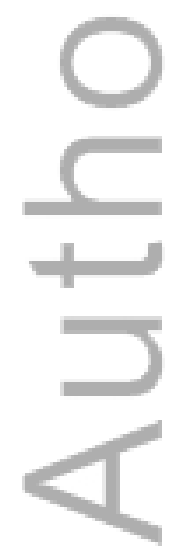


Table 1. Descriptive statistics for dependent variables and covariates, weighted, Fragile Families and Child Wellbeing Study, N=3,062

\begin{tabular}{|c|c|c|c|c|c|}
\hline \multirow[b]{2}{*}{ Variable } & \multicolumn{2}{|c|}{$\begin{array}{l}\text { Unmarried at } \\
\text { birth }\end{array}$} & \multicolumn{3}{|c|}{ Married at birth } \\
\hline & Mean & SE & Mean & SE & \\
\hline \multicolumn{6}{|l|}{ Outcomes } \\
\hline $\begin{array}{l}\text { Self-reported delinquency }(\mathrm{N}=2288,707) \\
\text { Mother-reported externalizing behavior ( } \mathrm{N}=2178 \text {, }\end{array}$ & 1.161 & 0.094 & 1.024 & 0.267 & * \\
\hline 690) & 5.693 & 0.316 & 4.574 & 0.435 & * \\
\hline Teacher-reported problem behavior $(\mathrm{N}=1494,530)$ & 3.527 & 0.232 & 2.044 & 0.246 & * \\
\hline \multicolumn{6}{|l|}{ Family structure and MPF history } \\
\hline No family structure transitions & 0.246 & 0.009 & 0.654 & 0.018 & * \\
\hline 1 family structure transition & 0.186 & 0.008 & 0.093 & 0.011 & $*$ \\
\hline 2 family structure transitions & 0.278 & 0.009 & 0.156 & 0.013 & $*$ \\
\hline $3+$ family structure transitions & 0.290 & 0.009 & 0.095 & 0.011 & $*$ \\
\hline Number of union transitions & 2.163 & 0.043 & 0.844 & 0.056 & $*$ \\
\hline Single partner fertility & 0.484 & 0.010 & 0.845 & 0.013 & $*$ \\
\hline 1+ older siblings have different father & 0.324 & 0.010 & 0.099 & 0.011 & $*$ \\
\hline $1+$ younger siblings have different father & 0.272 & 0.009 & 0.063 & 0.009 & $*$ \\
\hline Number of MPF partners & 0.840 & 0.019 & 0.223 & 0.018 & * \\
\hline \multicolumn{6}{|l|}{ Co-occurrence of family structure change and MPF } \\
\hline None & 0.132 & 0.007 & 0.590 & 0.018 & * \\
\hline Multipartner fertility (MPF) only & 0.114 & 0.007 & 0.064 & 0.009 & $*$ \\
\hline Family structure transitions only & 0.297 & 0.009 & 0.220 & 0.015 & * \\
\hline Family structure transitions and MPF & 0.456 & 0.010 & 0.125 & 0.012 & $*$ \\
\hline Full siblings in household & 0.871 & 0.023 & 1.442 & 0.037 & * \\
\hline \multicolumn{6}{|l|}{ Control variables } \\
\hline Mother is non-Hispanic white & 0.133 & 0.007 & 0.434 & 0.018 & * \\
\hline Mother is non-Hispanic black & 0.581 & 0.010 & 0.253 & 0.016 & $*$ \\
\hline Mother is non-Hispanic other race & 0.021 & 0.003 & 0.065 & 0.009 & $*$ \\
\hline Mother is Hispanic & 0.266 & 0.009 & 0.248 & 0.016 & \\
\hline Child is male & 0.515 & 0.010 & 0.547 & 0.018 & \\
\hline Child age in months & 112.484 & 0.092 & 112.132 & 0.157 & \\
\hline No. of minors in household & 1.802 & 0.028 & 1.630 & 0.040 & $*$ \\
\hline Mother has <HS diploma & 0.371 & 0.010 & 0.147 & 0.013 & $*$ \\
\hline Mother has HS diploma/GED & 0.354 & 0.010 & 0.193 & 0.015 & $*$ \\
\hline Mother has some college & 0.246 & 0.009 & 0.298 & 0.017 & * \\
\hline Mother has college+ & 0.029 & 0.003 & 0.362 & 0.018 & $*$ \\
\hline Mother depressed at year 1 & 0.218 & 0.009 & 0.159 & 0.014 & $*$ \\
\hline
\end{tabular}


Instability, Multipartner Fertility and Behavior

Birth covered by Medicaid

Any multipartner fertility in last two years

Any family structure transition in last two years

Number of prior partners

Child's temperament at age 1

Family context (measured at age 9)

No. of residential moves since birth

Mother's physical health

Mother-child closeness

Mother's harsh discipline

Income-to-needs ratio, ordinal (1-5)

Maternal self-reported depression

Father no longer living

No father-child contact in last 30 days

Father has children with other partner

Unknown if father has other children

Perceived financial support

Poor sibling relationship quality

N

* group differences significant at $p<.05$

$\begin{array}{lllll}0.746 & 0.009 & 0.273 & 0.016 & * \\ 0.138 & 0.007 & 0.034 & 0.007 & * \\ 0.058 & 0.005 & 0.046 & 0.008 & \\ 1.924 & 0.050 & 2.781 & 0.119 & * \\ 2.871 & 0.023 & 2.626 & 0.036 & *\end{array}$

$\begin{array}{lllll}3.113 & 0.413 & 1.908 & 0.329 & *\end{array}$

$\begin{array}{lllll}3.467 & 0.021 & 3.835 & 0.036 & *\end{array}$

$\begin{array}{llll}2.086 & 0.012 & 2.101 & 0.021\end{array}$

$\begin{array}{lllll}1.118 & 0.018 & 0.949 & 0.031 & *\end{array}$

$\begin{array}{lllll}2.710 & 0.026 & 3.891 & 0.046 & *\end{array}$

$\begin{array}{lllll}0.128 & 0.007 & 0.087 & 0.010 & *\end{array}$

$\begin{array}{llll}0.036 & 0.004 & 0.022 & 0.005\end{array}$

$\begin{array}{lllll}0.383 & 0.010 & 0.105 & 0.011 & *\end{array}$

$\begin{array}{lllll}0.253 & 0.009 & 0.065 & 0.009 & *\end{array}$

$\begin{array}{lllll}0.109 & 0.006 & 0.026 & 0.006 & *\end{array}$

$\begin{array}{lllll}2.593 & 0.017 & 2.786 & 0.022 & *\end{array}$

\begin{tabular}{lllll}
0.495 & 0.014 & 0.593 & 0.026 & $*$ \\
\hline
\end{tabular}

$2327 \quad 735$

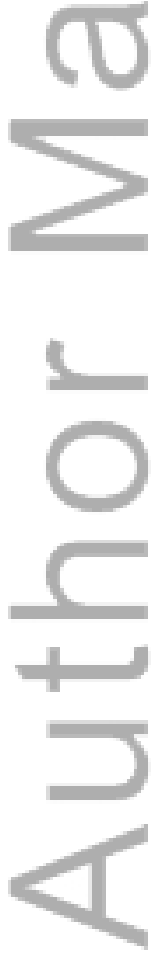

This article is protected by copyright. All rights reserved. 
Table 2. Group mean comparisons of dependent variables by family history, overall and by mother's union status at birth, weighted $(\mathrm{N}=3,062)$

\begin{tabular}{|c|c|c|c|c|c|c|c|c|c|}
\hline & \multicolumn{3}{|c|}{ Overall } & \multicolumn{2}{|c|}{$\begin{array}{c}\text { Unmarried at } \\
\text { birth }\end{array}$} & & \multicolumn{2}{|c|}{$\begin{array}{l}\text { Married at } \\
\text { birth }\end{array}$} & \\
\hline & Mean & SE & & Mean & SE & & Mean & SE & \\
\hline \multicolumn{10}{|l|}{ Child-reported delinquency $(N=2,995)$} \\
\hline \multicolumn{10}{|l|}{ Family structure instability } \\
\hline No family structure transitions & 0.996 & 0.280 & & 0.953 & 0.114 & & 1.012 & 0.383 & \\
\hline 1 transition & 0.986 & 0.106 & & 0.941 & 0.107 & & 1.092 & 0.245 & \\
\hline 2 transitions $=$ & 1.122 & 0.194 & & 1.337 & 0.267 & & 0.796 & 0.249 & \\
\hline $3+$ transitions & 0.140 & 0.146 & & 1.337 & 0.134 & $*$ & 1.564 & 0.415 & \\
\hline \multicolumn{10}{|l|}{ Multipartner fertility } \\
\hline No multipartner fertility & 0.972 & 0.200 & & 1.064 & 0.108 & & 0.926 & 0.296 & \\
\hline Older siblings have different father & 1.351 & 0.148 & & 1.157 & 0.108 & & 2.036 & 0.459 & * \\
\hline Younger siblings have different father & 1.353 & 0.226 & & 1.305 & 0.251 & & 1.601 & 0.484 & \\
\hline \multicolumn{10}{|c|}{ Mother-reported externalizing behavior $(N=2,868)$} \\
\hline \multicolumn{10}{|c|}{ Family structure instability } \\
\hline No family structure transitions & 4.262 & 0.436 & & 4.600 & 0.458 & & 4.194 & 0.564 & \\
\hline 1 transition & 6.016 & 0.752 & $*$ & 6.990 & 0.947 & $*$ & 7.086 & 1.103 & * \\
\hline 2 transitions & 5.567 & 0.543 & $*$ & 5.684 & 0.690 & & 5.608 & 0.878 & \\
\hline $3+$ transitions & 5.573 & 0.394 & $*$ & 6.109 & 0.365 & $*$ & 4.081 & 0.847 & \\
\hline \multicolumn{10}{|l|}{ Multipartner fertility } \\
\hline No multipartner fertility & 4.682 & 0.339 & & 5.039 & 0.340 & & 4.500 & 0.484 & \\
\hline Older siblings have different father & 6.172 & 0.499 & $t$ & 6.538 & 0.628 & $t$ & 4.976 & 0.543 & \\
\hline Younger siblings have different father & 6.293 & 0.602 & $t$ & 6.522 & 0.681 & & 5.184 & 1.115 & \\
\hline \multicolumn{10}{|c|}{ Teacher reported externalizing behavior $(N=2,024)$} \\
\hline \multicolumn{10}{|c|}{ Family structure instability } \\
\hline No family structure transitions & 1.932 & 0.185 & & 2.750 & 0.313 & & 1.621 & 0.230 & \\
\hline 1 transition & 3.327 & 0.590 & $*$ & 3.880 & 0.706 & & 1.784 & 0.438 & \\
\hline 2 transitions & 3.160 & 0.365 & $*$ & 3.535 & 0.451 & & 2.588 & 0.630 & \\
\hline $3+$ transitions & 4.524 & 0.533 & $*$ & 4.323 & 0.398 & $*$ & 5.517 & 1.729 & * \\
\hline \multicolumn{10}{|l|}{ Multipartner fertility } \\
\hline No multipartner fertility & 2.206 & 0.166 & & 3.202 & 0.288 & & 1.704 & 0.205 & \\
\hline Older siblings have different father & 4.223 & 0.439 & $*$ & 4.261 & 0.487 & $*$ & 4.056 & 1.026 & $t$ \\
\hline Younger siblings have different father & 4.147 & 0.543 & $*$ & 3.798 & 0.421 & & 6.160 & 2.201 & $t$ \\
\hline
\end{tabular}


$* p<.05$ compared to category in top row of each panel $t p<.10$ compared to category in top row of each panel

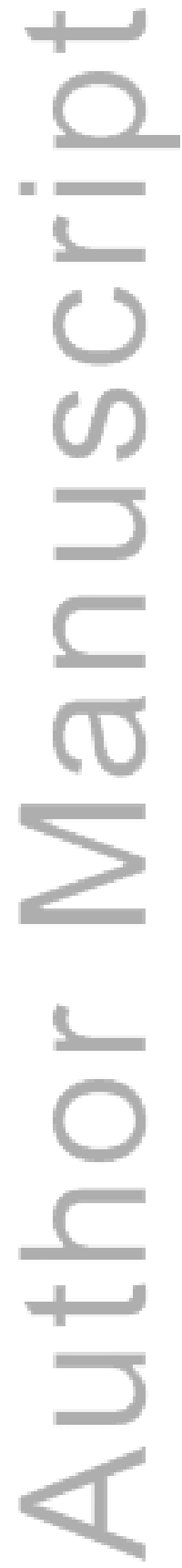


Table 3. Negative binomial regression results from models predicting self-reported delinquent behavior (unstandardized coefficients with standard errors beneath)

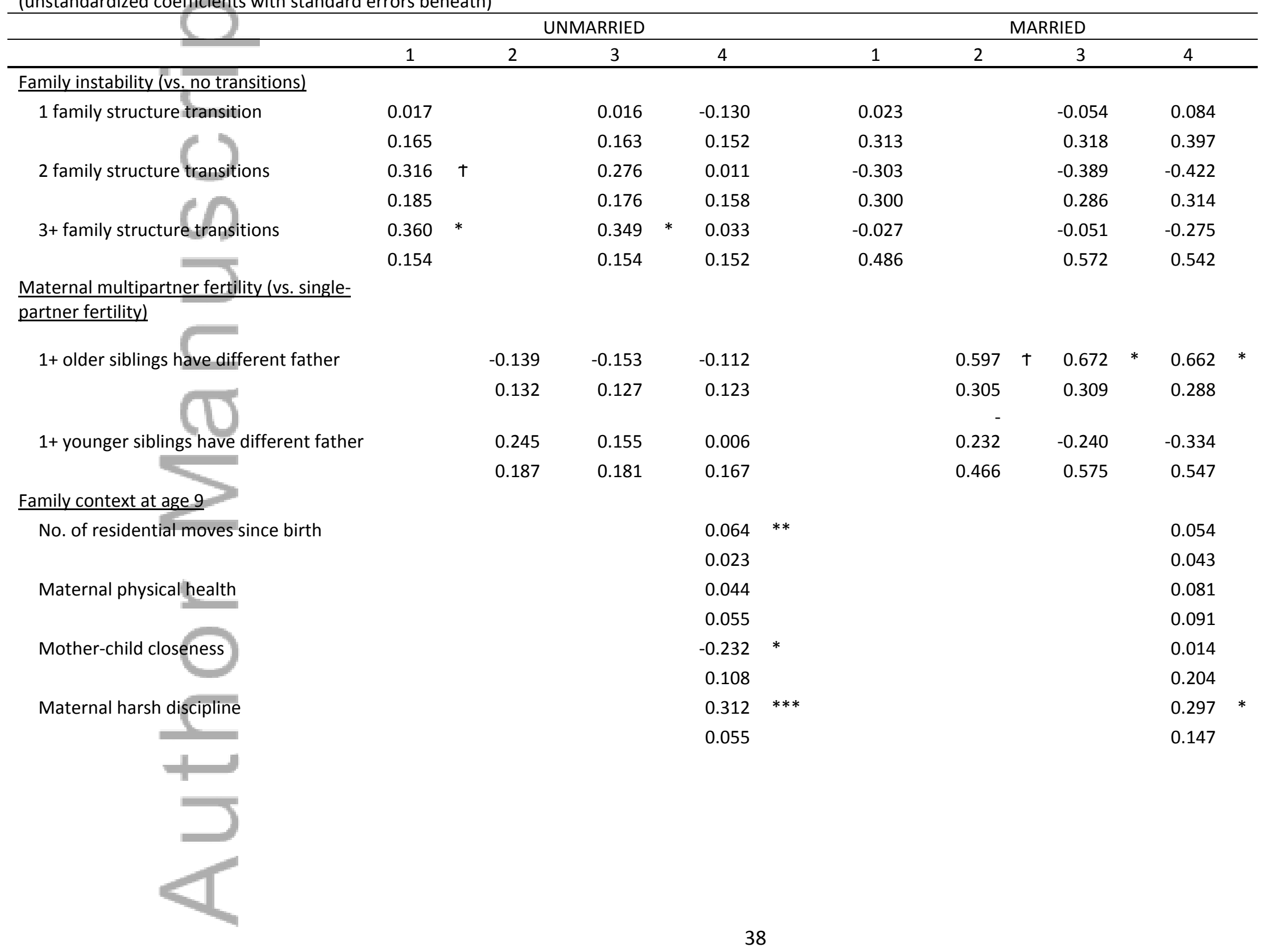

This article is protected by copyright. All rights reserved. 
Income-to-needs ratio, ordinal (1-5)

Mother meets criteria for self-reported depression (CIDI-SF)

\section{1}

Father involvement (Vs. seen father in last 30 days)

Father no longer living

Not seen father in last 30 days

Paternal multipartner fertility (vs. singlepartner fertility)

Biological father has children with other partner

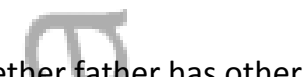

Unknown whether father has other children

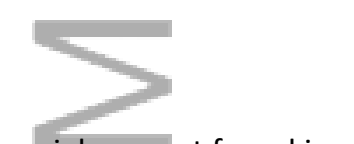

Perceived financial support from kin

Child has poor relationship quality with siblings
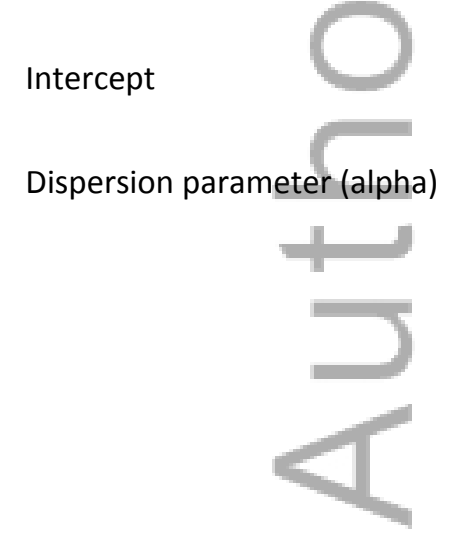

0.028

0.054

$-0.016$

0.136

$-0.027$

0.228

0.016

0.112

$-0.239$

0.106

0.183

0.337

$-0.154$

0.755

0.277

0.345

0.078

$-0.172$

0.133

0.366

$-0.043$

$-0.019$

0.174

0.861

0.090

0.125

0.058

0.197

0.214

0.202

0.078

0.130

0.407

1.695

0.515

0.403

1.09

1.646

$-1.138$

1.493

0.823

5.705

2.664

1.271

6.448
2.788
1.252

5.746

2.766

4.226

2.776

1.078

This article is protected by copyright. All rights reserved. 


\begin{tabular}{lrrrrrrrr} 
& 0.15 & 0.1522 & 0.1493 & 0.1326 & 0.3303 & 0.33 & 0.3202 & 0.295 \\
\hline $\mathrm{N}$ & 2288 & 2288 & 2288 & 2288 & 707 & 707 & 707 & 707 \\
$* * * \mathrm{p}<001 * * p<01 * p<05$ & & &
\end{tabular}

s also control for child gender and age in months at age $9 \cdot$ mother's race education and union status at child's birth; mother's number of partners prior to the birth; whether the birth was covered by Medicaid; mother's depression at age 1 ; child temperament at age 1 ; and whether any transition or multipartner fertility occurred in last two years; number of coresident full siblings at age 9.

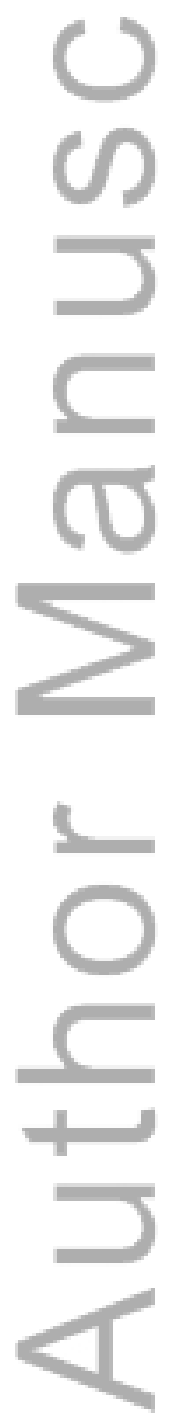

This article is protected by copyright. All rights reserved. 
Table 4. Negative binomial regression results from models predicting mother-reported externalizing behavior (unstandardized coefficients with standard errors beneath)

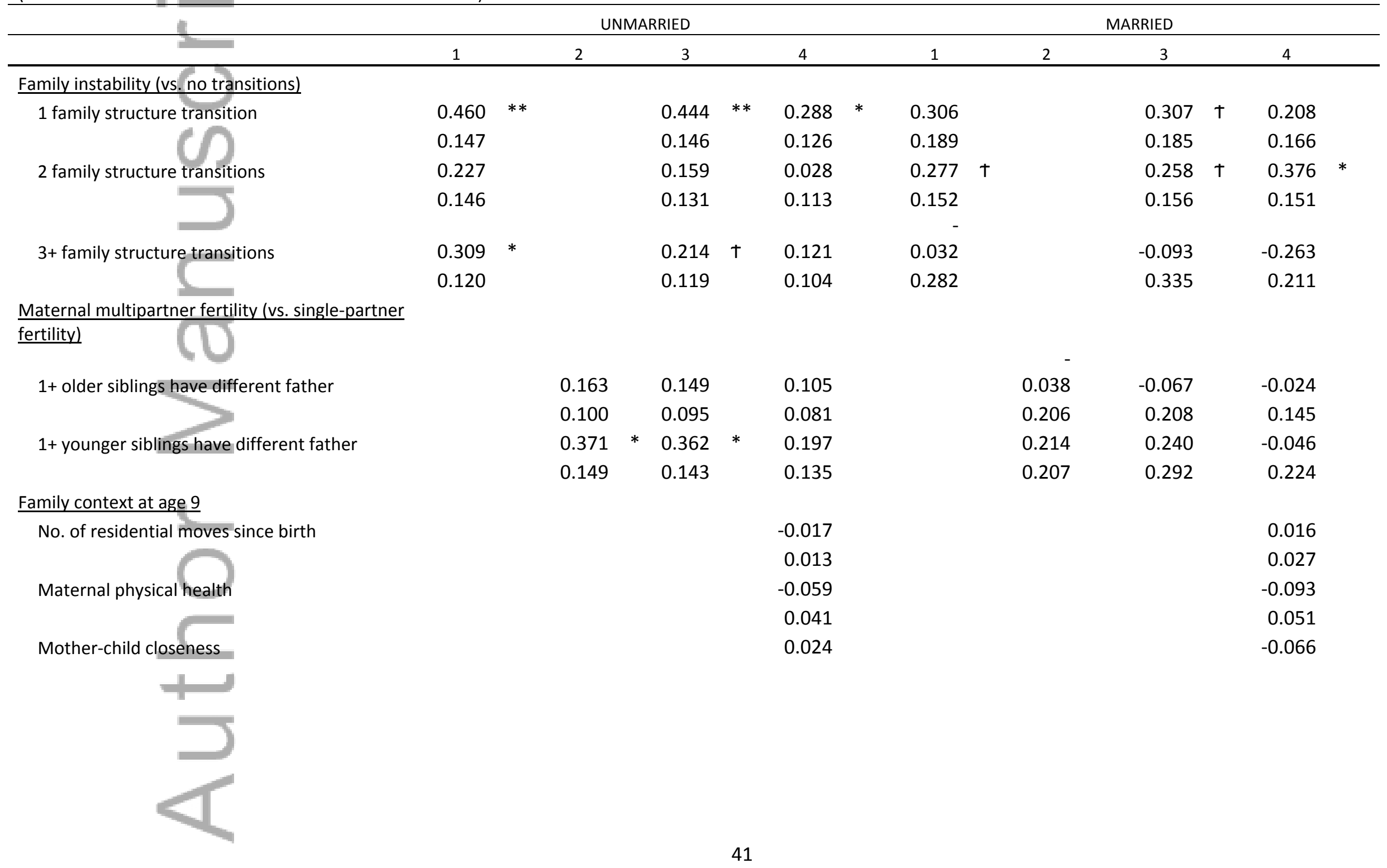

This article is protected by copyright. All rights reserved. 


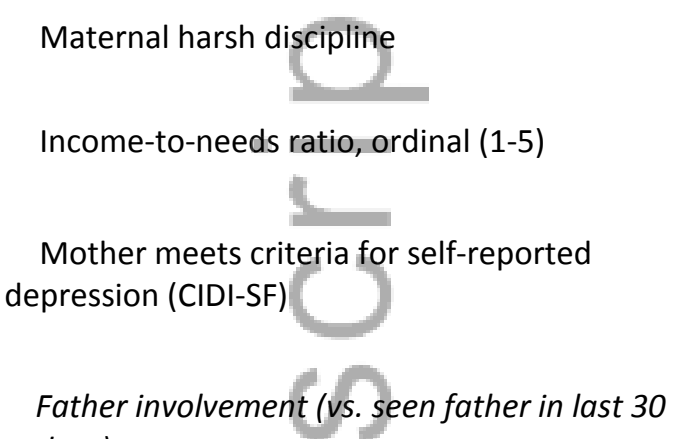

Mother meets criteria for self-reported depression (CIDI-SF)

Father involvement (vs. seen father in last 30 days)

Father no longer living

Not seen father in last 30 days

Paternal multipartner fertility (vs. singlepartner fertility)

Biological father has children with other

partner

Unknown whether father has other children

Perceived financial support from kin

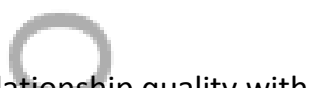

Child has poor relationship quality with

siblings

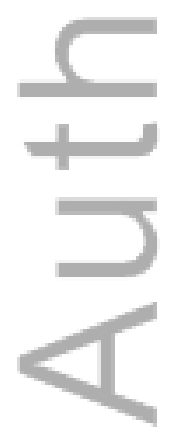

0.064

0.467

0.039

$-0.148$

0.035

$-0.015$

0.098

0.092

$0.559 * * *$

0.058

$-0.115$

0.054

0.061

0.151

0.053

0.372

0.282

$-0.008$

0.052

0.153

0.088

0.084

$-0.025$

0.186

0.089

0.463

0.227

0.183

0.093

0.094

0.017

0.079 
Instability, Multipartner Fertility and Behavior

\begin{tabular}{|c|c|c|c|c|c|c|c|c|c|c|c|}
\hline ע & 1.723 & 1.407 & 1.476 & 1.509 & 5.133 & $* *$ & 4.683 & $* *$ & 5.176 & $* *$ & 2.295 \\
\hline & 1.474 & 1.389 & 1.357 & 1.155 & 1.810 & & 1.799 & & 1.809 & & 1.541 \\
\hline Dispersion parameter (alpha) & 0.897 & 0.902 & 0.880 & 0.653 & 0.646 & & 0.662 & & 0.644 & & 0.326 \\
\hline$=$ & 0.0735 & 0.0773 & 0.072 & 0.0619 & 0.117 & & 0.121 & & 0.1166 & & 0.0786 \\
\hline
\end{tabular}

$* * * p<.001 * * p<.01 * p<.05+p<.10 ;$ all models also control for child gender and age in months at age 9; mother's race/ethnicity, education and union status at child's birth; mother's number of partners prior to the birth; whether the birth was covered by Medicaid; mother's depression at age 1 ; child temperament at age 1 ; and whether any transition or multipartner fertility occurred in last two years; number of coresident full siblings at age 9.

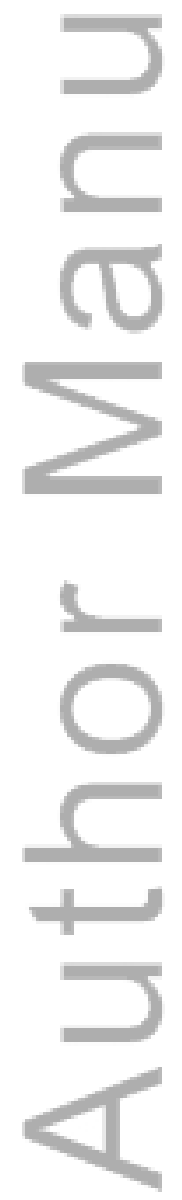

This article is protected by copyright. All rights reserved. 
Table 5. Negative binomial regression results from models predicting teacher-reported problem behavior (unstandardized coefficients with standard errors beneath)

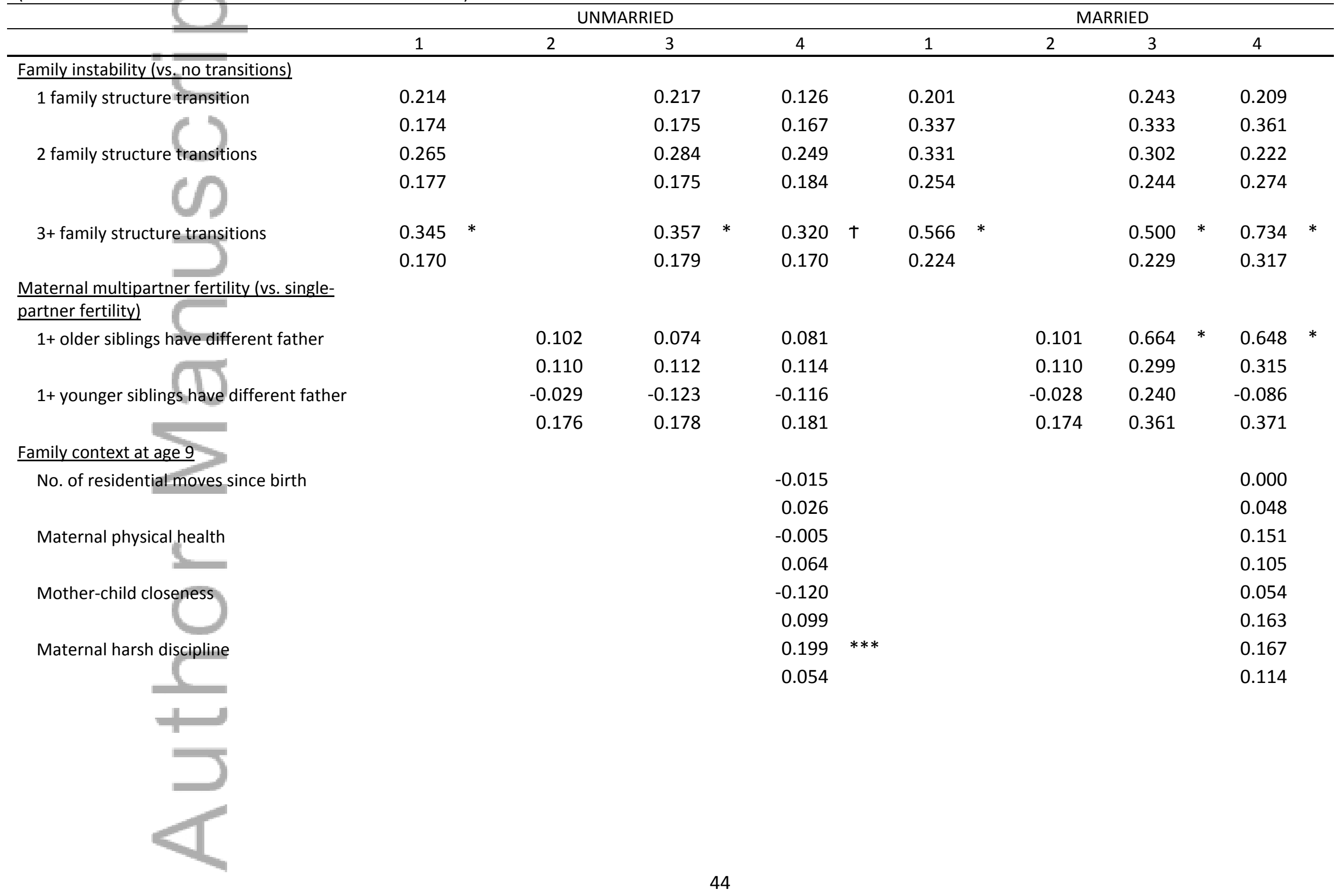

This article is protected by copyright. All rights reserved. 
Income-to-needs ratio, ordinal (1-5)

Mother meets criteria for self-reported depression (CIDI-SF)

Father involvement (Vs. seen father in last 30 days)

Father no longer living

Not seen father in last 30 days

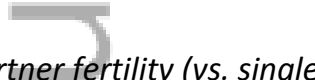

Paternal multipartner fertility (vs. singlepartner fertility)

Biological father has children with other partner

\section{Ar}

Unknown whether father has other children

Perceived financial support from kin

Child has poor relationship quality with siblings

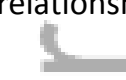

Intercept

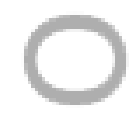

Dispersion parameter (alpha)
$-0.075$

0.049

0.169

0.121

0.244

0.191

0.137

0.128

$-0.080$

0.144

$-0.359$

0.171

0.005

0.075

$-0.056$

0.079

2.163

1.763

1.138

0.158
$0.154+$

0.092

0.346

0.277

0.234

0.462

$0.559 \dagger$

0.336

$-0.401$

0.372

0.225

0.577

0.009

0.140

0.083

0.127

2.357

2.355

2.340

1.1674

1.189

0.169

0.170

0.298

This article is protected by copyright. All rights reserved. 
1494

1494

530

530

530

530

$* * * p<.001 * * p<.01 * p<.05+p<.10 ;$ all models also control for child gender and age in months at age 9; mother's race/ethnicity, education and union status at child's birth; mother's number of partners prior to the birth; whether the birth was covered by Medicaid; mother's depression at age 1; child temperament at age 1; and whether any transition or multipartner fertility occurred in last two years; number of coresident full siblings at age 9.

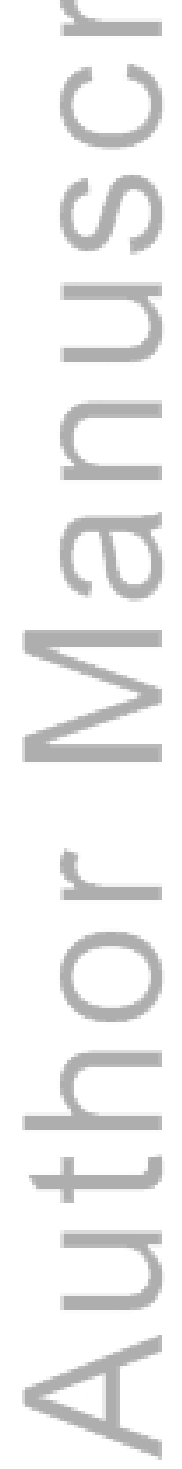

This article is protected by copyright. All rights reserved. 